\title{
Análise Facial Subjetiva
}

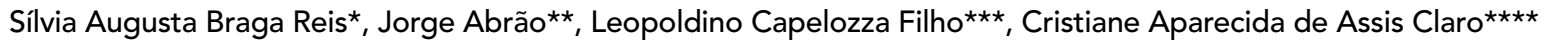

\begin{abstract}
Resumo
Introdução: a análise facial tem sido um recurso diagnóstico valorizado desde os primórdios da Ortodontia. Vários autores tentaram estabelecer referências de normalidade na direção das quais os pacientes ortodônticos deveriam ser tratados. Essa preocupação da Ortodontia está em concordância com a expectativa do paciente, cuja principal motivação para o tratamento ortodôntico é a melhora estética. Para que os objetivos do profissional possam solucionar a queixa do paciente é fundamental que o ortodontista conheça os parâmetros utilizados pela sociedade na avaliação estética. Sugerimos, por meio desse trabalho, uma nomenclatura que permita a realização da Análise Facial Subjetiva, estética e morfológica. Objetivo: avaliar a aplicação prática da análise. Metodologia: solicitou-se a um grupo heterogêneo de avaliadores (14 ortodontistas, 12 leigos e 7 artistas) que dessem notas ao perfil facial de 100 indivíduos (50 de cada gênero) classificando-os como esteticamente desagradáveis (notas 1, 2 ou 3), esteticamente aceitáveis (notas 4, 5 ou 6) e esteticamente agradáveis (notas 7, 8 ou 9). Resultados: $89 \%$ dos perfis foram esteticamente aceitáveis, $8 \%$ desagradáveis e 3\% agradáveis. Em 38,35\% das justificativas, o nariz foi a estrutura responsável pela estética desagradável, seguida pelo mento ("queixo") em 18,9\% dos relatos. Conclusão: foi possivel observar, portanto, que a Análise Facial Subjetiva é mais um instrumento diagnóstico, que tem sua importância aumentada por ser o parâmetro pelo qual o paciente e as pessoas com as quais ele convive vão avaliar os resultados do tratamento.
\end{abstract}

Palavras-chave: Análise facial. Estética. Ortodontia.

\section{INTRODUÇÃO}

A Odontologia moderna tem seu sucesso associado à união sinérgica de todas as especialidades, sejam elas Dentística, Prótese, Cirurgia ou Ortodontia, para a construção de um sorriso saudável, mas principalmente estético. Essa premissa está de acordo com as expectativas dos pacientes, que tem por principal motivação para o tratamento a melhora estética advinda do mesmo. Na Ortodon- tia, essa afirmação já foi comprovada por vários estudos. Segundo Giddon ${ }^{11}$, $80 \%$ dos adultos que procuram o tratamento ortodôntico para si ou para seus filhos, o fazem por motivações estéticas, independente das condições estruturais e funcionais. Esse autor só fez confirmar a observação já divulgada por Mckierman et al. ${ }^{24}$

Khan e Horrocks ${ }^{18}$ estudaram as motivações de 676 pacientes adultos que buscaram o tratamento

* Doutoranda em Ortodontia pela USP - São Paulo. Mestre em Ortodontia pela Universidade Metodista de São Paulo. Especialista em Ortodontia pela PROFIS - USP - Bauru. Professora Assistente do Departamento de Ortodontia da Universidade Metodista de São Paulo.

** Professor Livre Docente da Faculdade de Odontologia da Universidade de São Paulo.

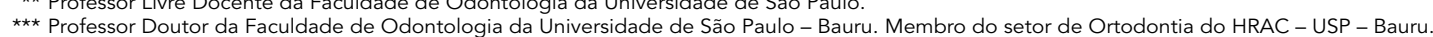

$\star \star \star \star$ Doutoranda em Ortodontia pela USP - São Paulo. Mestre em Odontologia. Especialista em Ortodontia. Professora Colaboradora Assistente da Disciplina de Ortodontia do Departamento de Odontologia da Universidade de Taubaté. 
ortodôntico e os resultados revelaram a estética seguida das disfunções articulares e da melhora da saúde dentária como os principais fatores motivadores.

A resistência dos ortodontistas em tratar pacientes sem queixas funcionais pode ser questionada em vista dos resultados obtidos por Varella e Garcia-Camba ${ }^{42}$ ao avaliarem longitudinalmente a auto-imagem de 40 pacientes adultos submetidos ao tratamento ortodôntico. Esses autores verificaram que os pacientes tinham a auto-imagem reduzida antes do tratamento e observaram uma melhora da mesma durante o tratamento. Outro aspecto interessante é que a autopercepção da face e dos dentes foi maior entre os indivíduos que procuraram o tratamento, possivelmente pelo desconforto que a aparência e o sorriso lhes impingia.

Porém, a evolução da Ortodontia como ciência ou a necessidade de estabelecer parâmetros de normalidade definidos como objetivos ortodônticos, resultou em um paradoxo entre os objetivos dos ortodontistas e de seus pacientes. Enquanto os pacientes desejam melhorar sua aparência, os ortodontistas baseiam-se principalmente nos desvios das relações físicas normativas entre dentição, esqueleto e tecido mole na definição do diagnóstico e do plano de tratamento ${ }^{11}$.

A necessidade científica e didática de estabelecer valores de normalidade para as inúmeras medidas lineares, angulares e proporcionais avaliadas em telerradiografias ou mesmo fotografias da face distanciaram o ortodontista da avaliação individual de cada face, princípio primário do diagnóstico, e levaram, muitas vezes, a opções de tratamento equivocadas que buscavam metas erroneamente definidas.

Essa revisão da evolução da especialidade tem sido realizada em vários momentos históricos. Em 1953, Tweed $^{41}$ reavaliou seus casos tratados em 25 anos, seguindo a filosofia proposta por Angle, de que a melhor harmonia facial seria obtida com todos os dentes em oclusão. Tweed ${ }^{41}$ observou que apenas 20\% dos pacientes apresentavam oclusão normal e adequada harmonia facial. A maioria deles portava desarmonia facial, devida à protrusão exagerada dos incisivos, exigindo retratamento. O equilíbrio foi então obtido às custas de exodontias, contrariando todas as filosofias vigentes até então.

A posição do incisivo inferior, avaliada na telerradiografia do perfil, passou então a definir a necessidade de exodontias a fim de obter um ângulo entre o longo eixo do incisivo inferior e o plano palatino de $90^{\circ} \pm 5^{\circ}$. Segundo Tweed ${ }^{41}$, esse parâmetro estava relacionado à estética facial agradável. A utilização destes e outros parâmetros cefalométricos na definição dos planos de tratamentos resultou em extrações desnecessárias e iatrogenias na estética facial, identificadas por autores da literatura norte-americana como dish face ou face côncava.

A perspectiva atual da prática e da pesquisa odontológica exige que o profissional se aproxime das expectativas do seu paciente ao definir a melhora da estética facial e do sorriso como o principal objetivo do tratamento, e a avaliação direta da face do paciente como seu principal recurso diagnóstico, a qual permite observar as características faciais harmoniosas e desarmoniosas como o paciente é avaliado por si mesmo e pelos seus pares. Ao paciente, definitivamente, não interessa que os ângulos e proporções de sua face estejam dentro de um "padrão de normalidade" se este padrão não se adequar às suas características étnicas e individuais. A principal aspiração do paciente é ser reconhecido como bonito, ou no mínimo normal, por si mesmo e pela sociedade, eliminando características desagradáveis do sorriso e de sua face.

Dentro dessa perspectiva, devemos entender como a população realiza a apreciação estética dos seus integrantes, para que possamos reproduzir essa avaliação na nossa rotina de diagnóstico. Para tanto, alguns conceitos de estética utilizados pela população devem ser entendidos.

\section{ESTÉTICA}

Conceitualmente, estética é a apreciação da 
beleza, ou a combinação de qualidades que proporcionam intenso prazer aos sentidos, às faculdades intelectuais e morais ${ }^{11}$. Portanto a identificação da beleza está relacionada a uma sensação de prazer diante da visualização de um objeto, um som, uma pessoa. Por ser uma sensação prazerosa, o conceito de beleza é próprio de cada indivíduo, sendo estabelecido a partir de valores individuais relacionados ao gênero, raça, educação e experiências pessoais; e a valores da sociedade como o ambiente e a publicidade (mídia), cada vez mais responsável pela globalização do conceito de beleza.

Inúmeros autores já tentaram definir características faciais responsáveis pela estética agradável (beleza). Wuerpel ${ }^{43}$, Herzberg ${ }^{13}$ e Brons ${ }^{4}$ observaram que a estética agradável estaria associada à harmonia e ao equilibrio entre as partes constituintes do perfil facial. Rickets ${ }^{39}$ e Jefferson ${ }^{15}$ observaram que a beleza estaria associada à coincidência das proporções faciais com a proporção áurea. Cunningham ${ }^{7}$, Peck $^{30}$ e Perret et al. ${ }^{33}$ associaram a beleza a características neonatais. Segundo esses autores, as faces consideradas mais atrativas seriam aquelas com olhos grandes e espaçados, área nasal pequena e mento pequeno, consideradas características neonatais, associadas a características de maturidade, como maxilares proeminentes, e de expressão, como sobrancelhas altas.

No afã de identificar a característica da beleza, Langlois e Roggman ${ }^{19}$, Langlois et al. ${ }^{20}$ e Perret et al. ${ }^{33}$ observaram que as faces esteticamente mais agradáveis seriam aquelas cujas medidas faciais coincidem com as medidas faciais médias da população a qual pertencem.

Todas essas teorias foram testadas em inúmeros trabalhos e não foi possivel estabelecer uma característica facial responsável pela beleza. Isso já havia sido observado por Perrin ${ }^{34}$ desde 1921. Esse autor estudou a atratividade e a repulsividade física, sob o ponto de vista da Psicologia, ao solicitar aos estudantes de Psicologia da Universidade do Texas que selecionassem os 25 homens e as 25 mulheres mais bonitos da escola. Analisando essa escolha, o autor observou que a seleção não foi baseada em qualquer característica do selecionado, mas no sentimento despertado pelo mesmo no avaliador. Esse sentimento estaria associado a uma variedade de características, nenhuma delas necessariamente presente em qualquer indivíduo da amostra selecionada. Ou seja, a beleza não está em qualquer característica do avaliado, mas nos olhos do avaliador.

Outro aspecto a salientar é que a apreciação da beleza varia para cada população em diferentes momentos históricos ${ }^{2,28,31}$ (Fig. 1). Devido à influência do ambiente e da mídia na formação do conceito de beleza dos indivíduos, esse parece ser mais uniforme entre os indivíduos de uma mesma população, que vivem em um mesmo ambiente no mesmo momento histórico, e sofre alterações com o passar do tempo. Esse fato é facilmente
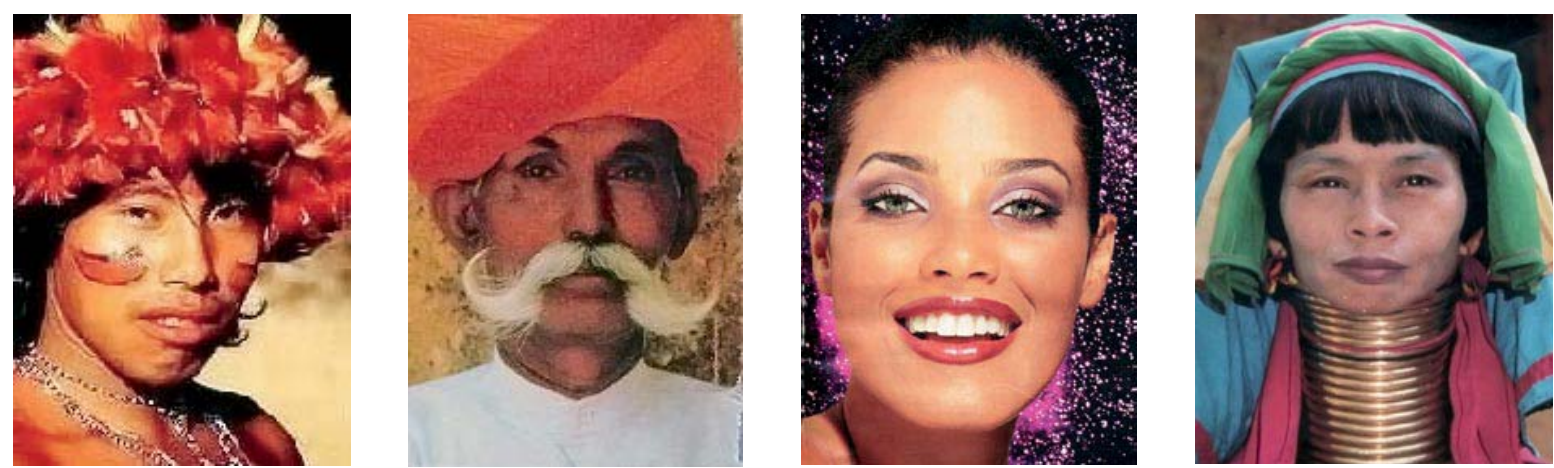

FIGURA 1 - A apreciação estética varia para cada população em diferentes momentos históricos. 
identificado na preferência por roupas, maquiagem ou cabelo.

Em 1970, Peck e Peck ${ }^{29}$ estudaram as características do perfil facial de ganhadoras de um concurso de beleza na região de Seattle. A grande diferença observada foi que, com o passar dos anos, as ganhadoras apresentavam o perfil labial cada vez mais protruso, ou seja, o padrão de beleza da face feminina mudou de um perfil labial reto para um perfil labial mais cheio. Esse achado foi comprovado pelos estudos realizados por Nguyen, Turley $^{28}$; Auger e Turley ${ }^{2}$. Esses autores estudaram fotografias do perfil facial de modelos fotográficos, retiradas das principais revistas de moda editadas desde o início do século XX. Os resultados demonstraram uma tendência dos padrões estéticos recentes preferirem lábios mais volumosos.

A partir da década de 90, o fenômeno da globalização passou a influenciar também o conceito de beleza das diferentes populações: a massiva exposição mundial a imagens semelhantes levou a uma tendência de homogeneização das preferências estéticas. Essa ocorrência foi observada em pesquisas realizadas por Perret et al. ${ }^{32,33}$, Mantzi$\operatorname{kos}^{23}$ e Alcalde et al. ${ }^{1}$ Esses autores observaram que, apesar das diferenças marcantes nas características faciais de japoneses e norte-americanos, essas populações mostraram o mesmo padrão de preferência frente ao mesmo estímulo facial. Após investigarem as características faciais e preferências estéticas de diferentes populações, entre elas uma de brasileiros e outra de norte-americanos, Jones e Hill ${ }^{17}$ verificaram que o perfil facial preferido pelos brasileiros apresentava medidas faciais próximas às médias do grupo norte-americano $\mathrm{e}$ bastante diferentes do padrão médio brasileiro.

Se considerarmos os cirurgiões-dentistas como responsáveis pela obtenção de sorrisos saudáveis e estéticos, o nível de satisfação dos pacientes ao final do tratamento depende não só da qualidade técnico-científica dos procedimentos, mas também da coincidência entre as expectativas do paciente e os objetivos do profissional.
Os estudos já realizados nos habilitam a afirmar que $80 \%$ dos pacientes desejam uma melhora estética da face e do sorriso, para ser reconhecido como normal na sociedade da qual fazem parte. Portanto, o ortodontista deve, ao início do tratamento, definir os objetivos e limitações do caso, estabelecendo um planejamento ortodôntico que dê ao paciente a melhor face e o melhor sorriso possíveis, esclarecendo ao paciente as possibilidades e limitações do seu caso, eliminando, dessa forma, expectativas irreais.

O objetivo do profissional só pode condizer com a expectativa do paciente se o ortodontista conhecer os parâmetros utilizados pela sociedade na avaliação estética dos seus membros. Para esta avaliação consideramos necessário criar uma nomenclatura que possibilite a realização da Análise Facial Subjetiva.

\section{ANÁLISE FACIAL SUBJETIVA ESTÉTICA}

A Análise Facial Subjetiva permite o estudo da avaliação estética realizada rotineiramente pela sociedade. Por meio dessa análise classificamos os indivíduos, de acordo com a agradabilidade estética, em esteticamente agradável, esteticamente aceitável e esteticamente desagradável.

Um dos objetivos dessa análise é facilitar a comunicação entre o paciente e os profissionais envolvidos no tratamento.

Essa nomenclatura foi anteriormente utilizada

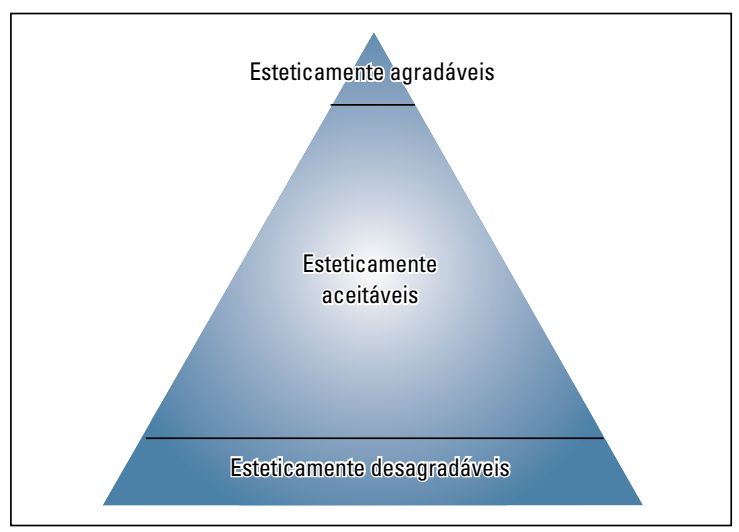

FIGURA 2 - Pirâmide de agradabilidade estética. 
por Neger e Newark ${ }^{27}$ que afirmaram ser a maioria da população composta por indivíduos esteticamente aceitáveis.

A partir dessa conceituação construímos a pirâmide de agradabilidade estética (Fig. 2). O objetivo do ortodontista deve ser realizar uma melhora do paciente na pirâmide. Os pacientes esteticamente desagradáveis devem ter a possibilidade de, ao final do tratamento, serem classificados como esteticamente aceitáveis e os pacientes esteticamente aceitáveis e agradáveis só podem ser submetidos a procedimentos que mantenham ou incrementem a classificação do paciente na pirâmide.

Com o intuito de avaliar a distribuição dos brasileiros, adultos, normais, ou seja, representativos da maioria da população, na Pirâmide de Agradabilidade, realizamos um estudo com uma amostra de 100 indivíduos (50 de cada gênero) leucodermas, com idade média de 23 anos e 7 meses, com desvio-padrão de 3 anos e 6 meses, variando de 18 a 36 anos (Tab. 1). A maioria da amostra foi constituída por alunos, professores e funcionários da Universidade Metodista de São Paulo.

Os critérios utilizados para a inclusão do indivíduo na amostra foram a presença de um adequado equilibrio muscular facial, representado pelo selamento labial passivo, ausência de tratamento ortodôntico ou cirurgia facial prévios e disponibilidade de participar deste estudo.

Para cada indivíduo da amostra foram obtidas

Tabela 1 - Análise comparativa dos gêneros com relação à idade (em anos).

\begin{tabular}{lccccccc}
\hline \multirow{2}{*}{ variável } & \multirow{2}{*}{ gênero } & \multicolumn{5}{c}{ medidas descritivas } & \multirow{2}{*}{ p } \\
\cline { 3 - 6 } & & $\begin{array}{c}\text { míni- } \\
\text { mo }\end{array}$ & $\begin{array}{c}\text { máxi- } \\
\text { mo }\end{array}$ & média & d.p. & \\
\hline \multirow{3}{*}{ idade } & feminino & 18,8 & 33,2 & 23,4 & 2,9 & \\
& & & & & & 0,57 n.s. \\
& masculino & 18 & 36 & 23,8 & 3,9 & $\mathrm{~F}=\mathrm{M}$ \\
\hline
\end{tabular}

Nota: 0 valor de $\mathrm{p}$ refere-se ao teste $t$ de Student para amostras independentes.

Legenda: $\mathrm{F}$ - feminino; $\mathrm{M}$ - masculino; n.s. - não significante.

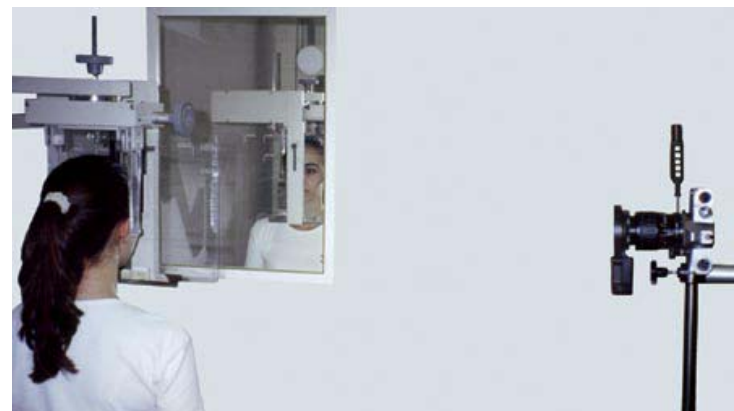

FIGURA 3 - Posição da máquina e do paciente no momento da tomada fotográfica padronizada do perfil.

fotografias faciais padronizadas do perfil facial ${ }^{37}$ (Fig. 3).

Diversos estudos já realizados nessa linha de pesquisa demonstraram que qualquer amostra de avaliadores deve ser a maior e mais heterogênea possível, com o objetivo de reduzir influências individuais ${ }^{10,14,35}$.

$\mathrm{Na}$ literatura estudada observou-se uma tendência dos diversos autores selecionarem artistas ${ }^{5}$, $\operatorname{ortodontistas}^{3,8,36}$, leigos ${ }^{10,14,16,17,19,22,33,40}$ e diferentes combinações desses 3 grupos $^{9,12,21,35}$, na composição de suas amostras de avaliadores.

Seguindo essa tendência, o grupo de avaliadores do presente trabalho foi constituído por ortodontistas e leigos de ambos os gêneros e artistas do gênero feminino, totalizando 32 indivíduos. Procuramos compor um grupo maior e mais heterogêneo possível, cujos indivíduos apresentassem

Tabela 2 - Caracterização dos avaliadores com relação à idade (em anos).

\begin{tabular}{ccccc}
\hline \multirow{2}{*}{ avaliador } & \multicolumn{4}{c}{ medidas descritivas } \\
\cline { 2 - 5 } & mínimo & máximo & média & d.p. \\
\hline $\begin{array}{c}\text { ortodontista } \\
\text { masculino }\end{array}$ & 36 & 56 & 44,7 & 7,8 \\
$\begin{array}{c}\text { ortodontista } \\
\text { feminino }\end{array}$ & 35 & 53 & 40,4 & 5,8 \\
$\begin{array}{c}\text { leigo masculino } \\
\text { leigo feminino }\end{array}$ & 27 & 53 & 35,7 & 9,2 \\
artista feminino & 21 & 40 & 30,7 & 8,9 \\
\hline
\end{tabular}


diferentes conceitos estéticos decorrentes de sua formação profissional, individual e social.

Portanto, a banca selecionada para classificar esteticamente a amostra foi composta por 14 ortodontistas ( 7 homens e 7 mulheres), 12 leigos à área odontológica e não vinculados a qualquer atividade artística (6 homens e 6 mulheres) e 6 artistas do gênero feminino ( 1 professora e 5 alunas de pós-graduação em artes da Escola de Belas Artes), todos residentes nas cidades de São Paulo, São Bernardo do Campo ou Santo André.

A idade média dos avaliadores foi de 37 anos e 6 meses com desvio-padrão de 9 anos e variou entre 21 e 56 anos.

A tabela 2 apresenta as idades médias, os desvios-padrão e os valores mínimos e máximos para cada grupo de avaliadores.

Entregamos aos avaliadores, individualmente, um álbum contendo todas as fotografias do perfil facial dispostas de maneira que o examinador visse apenas uma fotografia por vez. As fotografias dos gêneros feminino e masculino foram misturadas, através de sorteio, com o objetivo de reduzir a tendenciosidade na avaliação. No projeto piloto pôde-se observar que a análise consecutiva das faces do mesmo gênero favorecia a avaliação comparativa dos perfis. A distribuição aleatória das fotos procurou romper o padrão de comparação, na medida em que uma seqüência de perfis do mesmo gênero fosse interrompida por um perfil do gênero oposto.

Solicitamos aos examinadores que classificassem cada fotografia em um tempo máximo de 30 segundos, de acordo com a sua opinião em:

a) esteticamente agradável: notas 7,8 ou 9 ;

b) esteticamente aceitável: notas 4,5 ou 6 ;

c) esteticamente desagradável: notas 1, 2 ou 3 .

Foram classificados no Grupo Esteticamente Agradável os indivíduos que obtiveram, com maior freqüência, notas de 7 a 9, no Grupo Esteticamente Aceitável aqueles que obtiveram, com maior freqüência, notas de 4 a 6 e, finalmente, no Grupo Esteticamente Desagradável ficaram os que apresentaram, com maior freqüência, notas de 1 a 3.

Com o objetivo de avaliar a concordância intraexaminador na avaliação subjetiva do perfil, selecionamos, aleatoriamente, 10 fotografias do perfil facial e solicitamos aos examinadores que repetissem a classificação estética, com, no mínimo, uma semana de intervalo entre as duas avaliações.

Para a análise do erro da avaliação utilizamos o teste $t$ de Student para amostras pareadas. Não houve diferença significante entre a primeira e a segunda nota dos avaliadores, em nível de significância de $5 \%(\mathrm{p}>0,05)$.

$\mathrm{Na}$ tabela 3 são apresentadas as médias, os valores mínimos e máximos e os desvios-padrão para a primeira e a segunda avaliação.

Os resultados da Análise Facial Subjetiva mostraram que $89 \%$ dos indivíduos foram classificados como esteticamente aceitáveis, 3\% agradáveis e $8 \%$ desagradáveis (Gráf. 1). Se considerarmos que, na seleção dessa amostra, tínhamos a intenção de reunir um grupo de indivíduos normais, representativos da maioria da população dos adultos, leucodermas dessa região geográfica, esses resultados são consistentes, pois segundo Neger e Newark ${ }^{27}$ a maioria da população é esteticamente aceitável. Deve-se salientar também a excepcionalidade da face agradável, restrita a poucos indivíduos localizados no topo da pirâmide ${ }^{6}$.

No gênero feminino verificamos $6 \%$ esteticamente agradáveis, $90 \%$ esteticamente aceitáveis e

Tabela 3 - Avaliação do erro intra-examinador na Análise Facial Subjetiva do perfil.

\begin{tabular}{cccccccc}
\hline \multicolumn{5}{c}{} & \multicolumn{5}{c}{ medidas descritivas } & p \\
\cline { 2 - 6 } & medida & mínimo & máximo & média & d.p. & \\
\hline \multirow{2}{*}{ perfil } & primeira & 1 & 9 & 4,9 & 1,6 & \\
& & & & & & 0,357 n.s. \\
& segunda & 2 & 9 & 4,9 & 1,5 & $\mathrm{P}=\mathrm{S}$ \\
\hline
\end{tabular}

Nota: 0 valor de $\mathrm{p}$ refere-se ao teste $\mathrm{t}$ de Student para amostras pareadas.

Legenda: P - primeira avaliação; S - segunda avaliação;

n.s. - não significante. 


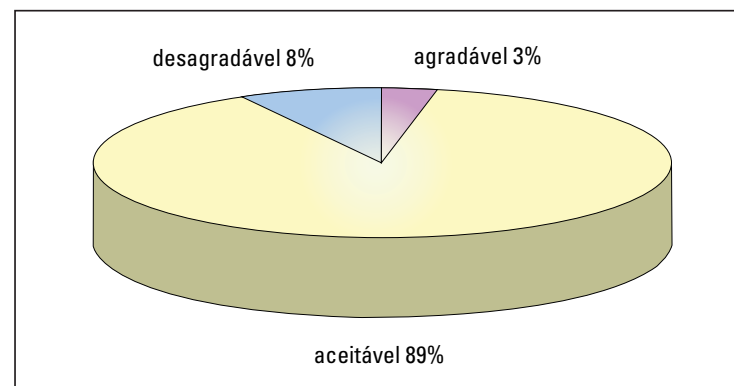

GRÁFICO 1 - Representação gráfica dos grupos da Análise Facial Subjetiva do perfil.

$4 \%$ esteticamente desagradáveis. No gênero masculino nenhum indivíduo foi classificado como esteticamente agradável na avaliação do perfil, $88 \%$ foram classificados esteticamente aceitáveis e 12\% esteticamente desagradáveis (Gráf. 2).

Giddon ${ }^{11}$ sugeriu que a utilização da palavra correta para o julgamento facial é muito importante e considerou o termo aceitável como o mais indicado para denominar faces estéticas, enquanto as faces não estéticas deveriam ser classificadas como inaceitáveis.

Utilizando essa nomenclatura, podemos considerar que $92 \%$ dos perfis dessa amostra foram esteticamente aceitáveis, enquanto apenas $8 \%$ foram esteticamente inaceitáveis. Devemos salientar, entretanto, que a utilização dos conceitos aceitável e inaceitável no momento da avaliação poderiam conduzir a resultados diferentes dos observados.

Os pacientes dessa amostra tinham como característica em comum o selamento labial passivo. Verificamos que, se o paciente apresenta esse selamento, ele tem mais de $90 \%$ de chance de ser reconhecido como esteticamente aceitável ou agradável e, portanto, o selamento labial passivo passa a ser considerado como um objetivo a ser alcançado durante o tratamento ortodôntico. O selamento labial passivo reduz a repercussão de discrepâncias dentárias ou esqueléticas na face e é, por esse motivo, um importante objetivo do tratamento ortodôntico.

Vários estudos já tentaram determinar as características faciais responsáveis por uma aparência

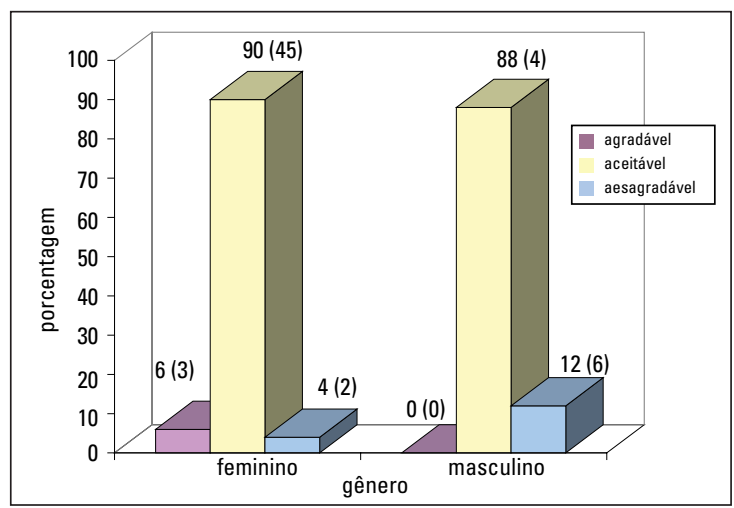

GRÁFICO 2 - Representação gráfica dos grupos da Análise Facial Subjetiva do perfil nos gêneros feminino e masculino.

estética agradável ou desagradável. Morris ${ }^{25}$; Nanda, Gosh ${ }^{26}$ e Brons ${ }^{4}$ associaram a estética agradável à harmonia e equilíbrio entre as partes do perfil facial. Perrin ${ }^{34}$ identificou, no perfil feminino, a forma do mento e, no masculino, a boca e os lábios como partes importantes na avaliação estética, porém observou que a classificação estética dos indivíduos não é baseada em qualquer característica do avaliado, mas no sentimento despertado pelo mesmo no avaliador.

Cox e Van der Linden ${ }^{9}$ associaram o aumento da convexidade do perfil à aparência estética desagradável. Em 1976, Terry e Davis ${ }^{40}$ observaram que os componentes faciais mais importantes na avaliação estética da face foram primeiro a boca, seguida dos olhos, estrutura facial, cabelo e nariz, nessa ordem. Cunningham ${ }^{7}$, Peck ${ }^{30}$ e Perret et al. ${ }^{33}$ sugeriram que os indivíduos esteticamente agradáveis seriam aqueles com características faciais neonatais. Por sua vez, Langlois e Roggman ${ }^{19}$ e Langlois et al. ${ }^{20}$ identificaram, nos indivíduos esteticamente agradáveis, as medidas faciais médias da população à qual pertenciam, sugerindo que a face percebida como agradável é a face média da população.

Brons ${ }^{4}$ observou que a face harmoniosa é vista como uma unidade, enquanto na face desarmoniosa a atenção é atraída pelo elemento que está fora de equilíbrio, denominado pelo autor de "elemento discordante". 
Tabela 4 - Justificativas apresentadas pelos examinadores para classificação dos indivíduos esteticamente desagradáveis

\begin{tabular}{|c|c|c|c|c|}
\hline \multirow[b]{3}{*}{ justificativa } & \multicolumn{4}{|c|}{ gênero } \\
\hline & \multicolumn{2}{|c|}{ feminino } & \multicolumn{2}{|c|}{ masculino } \\
\hline & n & $\%$ & $\mathbf{n}$ & $\%$ \\
\hline nariz & 24 & 40,7 & 64 & 35,8 \\
\hline queixo & 8 & 13,6 & 37 & 20,7 \\
\hline maxila & 7 & 11,9 & 3 & 1,7 \\
\hline olhos & 4 & 6,8 & 2 & 1,7 \\
\hline boca & 3 & 5,1 & 9 & 5 \\
\hline pele & 3 & 5,1 & 6 & 3,4 \\
\hline lábios & 2 & 3,4 & 10 & 5,6 \\
\hline ângulo nasolabial & 2 & 3,4 & 9 & 5 \\
\hline perfil & 2 & 3,4 & 3 & 1,7 \\
\hline testa & 1 & 1,7 & 4 & 2,2 \\
\hline $\begin{array}{c}\text { excesso de tecido } \\
\text { mole }\end{array}$ & 1 & 1,7 & 1 & 0,6 \\
\hline face longa & 1 & 1,7 & 1 & 0,6 \\
\hline pescoço & 1 & 1,7 & 0 & 0 \\
\hline $\begin{array}{l}\text { ângulo queixo- } \\
\text { pescoço }\end{array}$ & 0 & 0 & 15 & 8,4 \\
\hline $\begin{array}{l}\text { linha queixo- } \\
\text { pescoço }\end{array}$ & 0 & 0 & 4 & 2,2 \\
\hline $\begin{array}{l}\text { terço inferior da } \\
\text { face }\end{array}$ & 0 & 0 & 3 & 1,7 \\
\hline sulco mentolabial & 0 & 0 & 2 & 1,1 \\
\hline bochecha & 0 & 0 & 2 & 1,1 \\
\hline terço médio da face & 0 & 0 & 1 & 0,6 \\
\hline $\begin{array}{l}\text { altura facial ante- } \\
\text { rior inferior }\end{array}$ & 0 & 0 & 1 & 0,6 \\
\hline olhar & 0 & 0 & 1 & 0,6 \\
\hline rosto & 0 & 0 & 1 & 0,6 \\
\hline total & 59 & 100 & 179 & 100 \\
\hline
\end{tabular}

Nessa pesquisa, procuramos identificar as estruturas faciais associadas à aparência estética desagradável. Os avaliadores foram estimulados a justificarem quando classificavam um indivíduo como esteticamente desagradável.

Em 38,35\% das justificativas para desagradabilidade do perfil facial, o nariz foi a estrutura responsabilizada, seguida pelo mento ("queixo") em $18,9 \%$ dos relatos. Deve-se salientar o fato de que o nariz grande e o queixo pequeno, responsáveis por um aumento da convexidade facial, foram os principais fatores responsáveis pela estética facial desagradável, concordando com os achados de Cox e Van Der Linden ${ }^{9}$. Considerando a presença de leigos como agentes avaliadores, e a não indução de termos na justificativa, as justificativas para desagradabilidade incluíram também "olhar", "pele", "rosto", "sobrancelha", como pode ser observado na tabela 4, sugerindo que, muito mais que a harmonia entre as partes esqueléticas, a beleza facial, ou a sua ausência, é definida pelo conjunto de características faciais que muitas vezes estão fora da capacidade de intervenção do dentista, mas que, se reconhecidas pelo profissional podem ser devidamente abordadas evitando expectativas irreais com o tratamento ou até a intervenção de outros profissionais que possam auxiliar na promoção da beleza.

\section{Análise Facial Subjetiva morfológica}

A análise morfológica da face é o principal recurso diagnóstico para determinação do Padrão Facial ${ }^{6}$.

A organização do diagnóstico ortodôntico de acordo com os Padrões Faciais, extensamente abordados no livro Diagnóstico em Ortodontia, publicado em $2004^{6}$, permite abordar o tratamento das más oclusões, considerando a localização da discrepância esquelética, quando presente, a etiologia da má oclusão, estabelecendo protocolos de tratamento específicos para cada Padrão em cada faixa etária, com protocolos em curto prazo e perspectivas em longo prazo previsíveis, considerando a gravidade da discrepância.

Os benefícios dessa nova visão da Ortodontia dependem, entretanto, do diagnóstico adequado do Padrão Facial.

Considerando a limitação das medidas faciais em expressar forma ou normalidade ${ }^{38}$, a classificação do Padrão deve ser realizada pela avaliação morfológica da face nas visões frontal e lateral.

Os indivíduos podem ser classificados como Padrão I, II, III, Face longa ou Face curta. 
O Padrão I é identificado pela normalidade facial (Fig. 4). A má oclusão, quando presente, é apenas dentária não associada a qualquer discrepância esquelética sagital ou vertical. Os Padrões II e III são caracterizados pelo degrau sagital respectivamente positivo e negativo entre a maxila e a mandibula. Nos Padrões face longa e face curta a discrepância é vertical. Nos pacientes com erros esqueléticos, as más oclusões são geralmente conseqüentes dessas discrepâncias.

$\mathrm{Na}$ avaliação do perfil, o Padrão I é caracterizado por um grau moderado de convexidade. A expressão da maxila na face é identificada pela presença da projeção zigomática e depressão infraorbitária, que podem ser verificadas também na visão frontal. A linha de implantação do nariz, levemente inclinada para anterior, denota adequada posição maxilar. O sulco naso-geniano com leve inclinação posterior completa a avaliação do equilíbrio maxilar. $O$ ângulo nasolabial avalia a base nasal em relação ao lábio superior, cuja posição é fortemente determinada pela inclinação dos incisivos superiores. Portanto, esse ângulo pode estar adequado, aberto ou fechado nos pacientes Padrão I, como conseqüência da posição dos dentes anteriores superiores, independente do bom posicionamento maxilar, sempre observado nestes pacientes ${ }^{6}$.

O equilibrio mandibular, tamanho, forma e posição, podem ser verificados na avaliação do perfil por meio da linha queixo-pescoço. Ela deve ser expressiva sem ser excessiva e tender ao paralelismo com o Plano de Camper. Esse paralelismo contribui para um ângulo adequado entre as linhas do queixo e do pescoço. Além disso, esperase um ângulo mentolabial agradável esteticamente e construído com igual participação do lábio e do mento ${ }^{6}$.

Os pacientes portadores dos Padrões II e III apresentam discrepância sagital entre a maxila e a mandíbula, identificada, principalmente, na avaliação lateral da face. Indivíduos classificados como Padrão I na visão frontal e II ou III no per- fil apresentam melhor prognóstico que aqueles Padrões II ou III nas visões frontal e lateral, nos quais o desequilíbrio é grave o suficiente para ser identificado na avaliação de frente, devido às suas conseqüências verticais.

O Padrão II apresenta convexidade facial aumentada, em conseqüência do excesso maxilar, mais raro, ou pela deficiência mandibular ${ }^{6}$ (Fig. 5). Normalmente, observa-se uma maxila com boa expressão na face, enquanto o terço inferior está deficiente e com a linha queixo-pescoço curta. Apresenta, usualmente, um ângulo nasolabial bom, associado ao sulco mentolabial marcado pela eversão do lábio inferior.

No Padrão III a convexidade facial apresenta-se reduzida, resultando em um perfil reto ou mais raramente côncavo devido à deficiência maxilar, ao prognatismo mandibular ou à associação de ambos (Fig. 6). O terço médio da face tende a parecer deficiente, mesmo que esteja normal, pois o excesso mandibular desloca para anterior o tecido mole da maxila, mascarando a leitura da projeção zigomática ${ }^{6}$. O terço inferior da face tende ao aumento, principalmente no prognatismo e a linha queixo-pescoço apresenta-se normal nos deficientes maxilares ou em excesso nos prognatas. $\mathrm{O}$ sulco mentolabial encontra-se aberto, devido à verticalização compensatória dos incisivos inferiores.

Os pacientes classificados como Padrões Face Longa e Face Curta apresentam uma discrepância vertical visível nas avaliações de frente e perfil. O paciente Padrão Face Longa é caracterizado pelo excesso na altura facial, resultando em ausência de selamento labial, excesso de exposição de dentes no repouso e de gengiva no sorriso (Fig. 7). A convexidade facial desses pacientes está aumentada, a expressão maxilar é deficiente e a linha queixo-pescoço curta. O paciente Padrão Face longa tem deficiência na expressão sagital da maxila e da mandíbula, que apresentam direção de crescimento predominantemente vertical.

O paciente Padrão Face Curta é identificado 

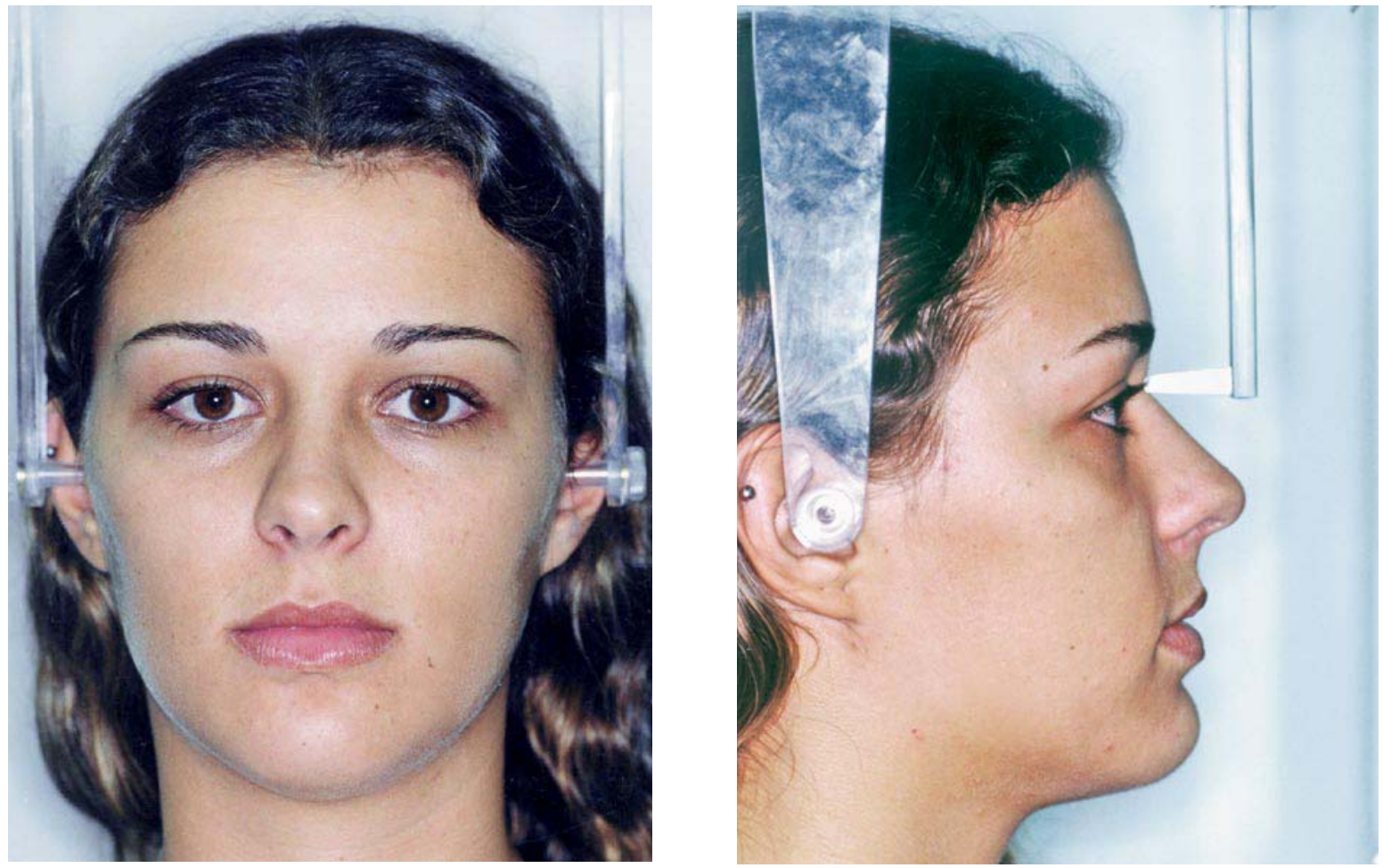

FIGURA 4 - Fotografias faciais frontal e lateral de paciente Padrão I.
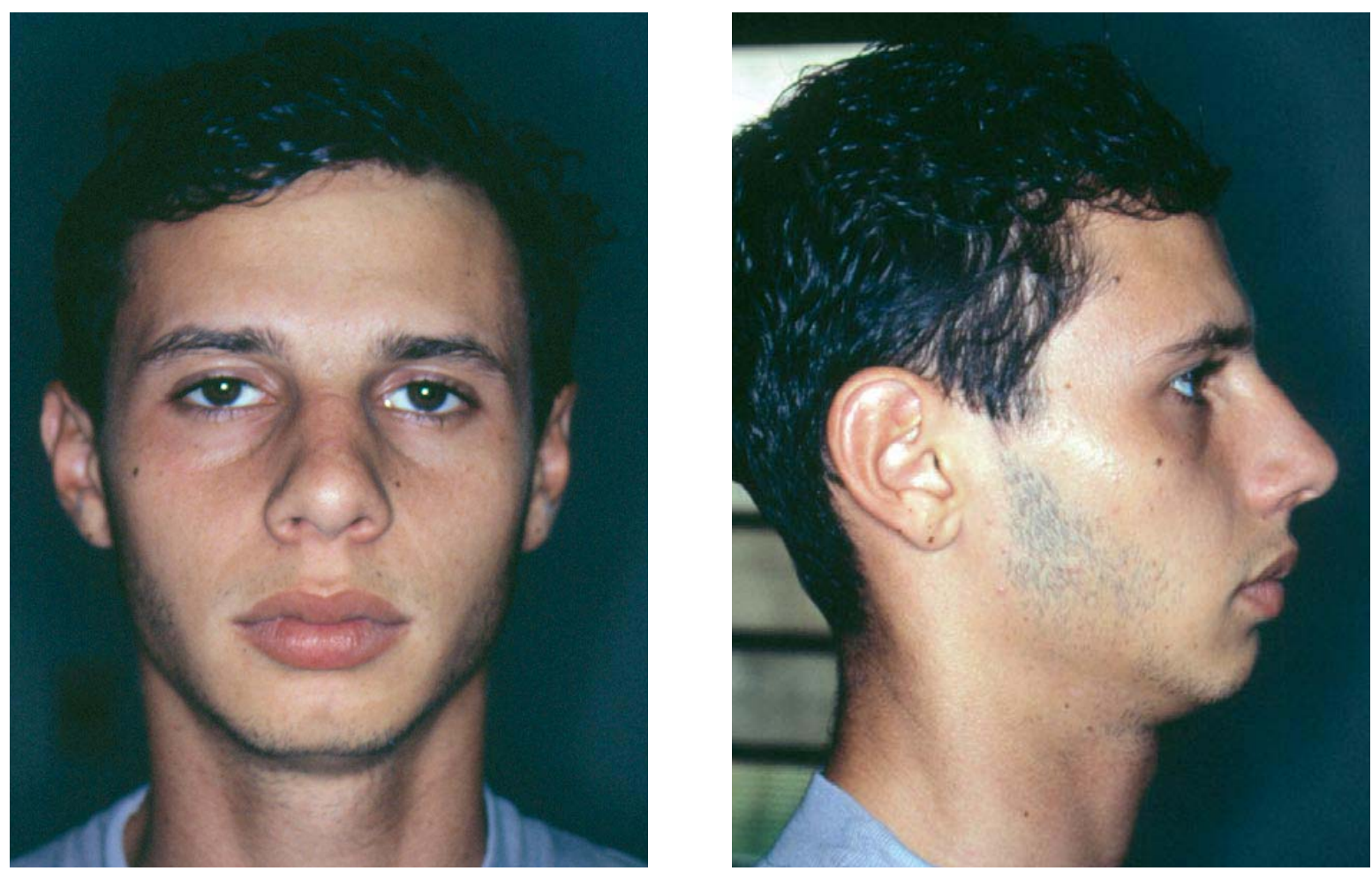

FIGURA 5 - Fotografias facias frontal e lateral de paciente Padrão II. 
REIS, S. A. B.; ABRÃO, J.; CAPELOZZA FILHO, L.; CLARO, C. A. A.

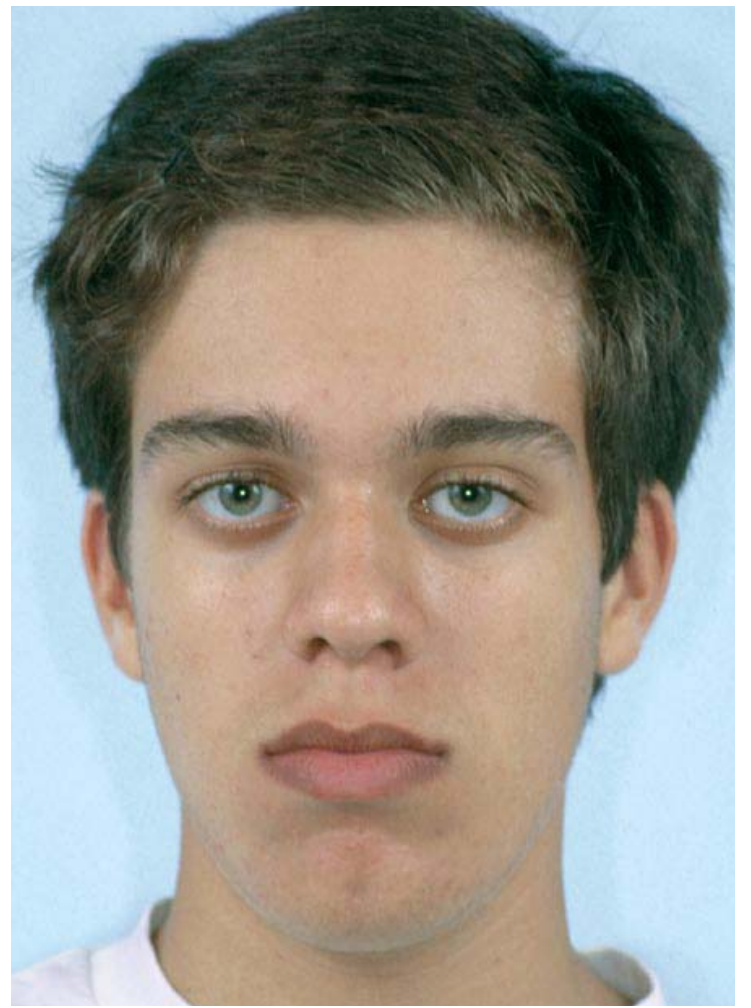

FIGURA 6 - Fotografias faciais frontal e lateral de paciente Padrão III.

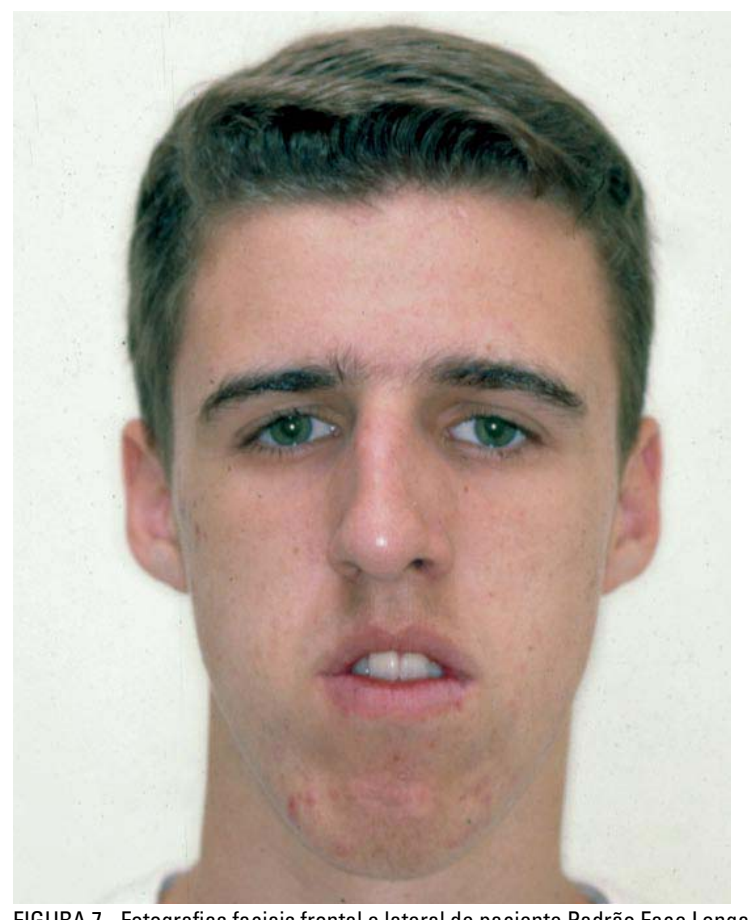

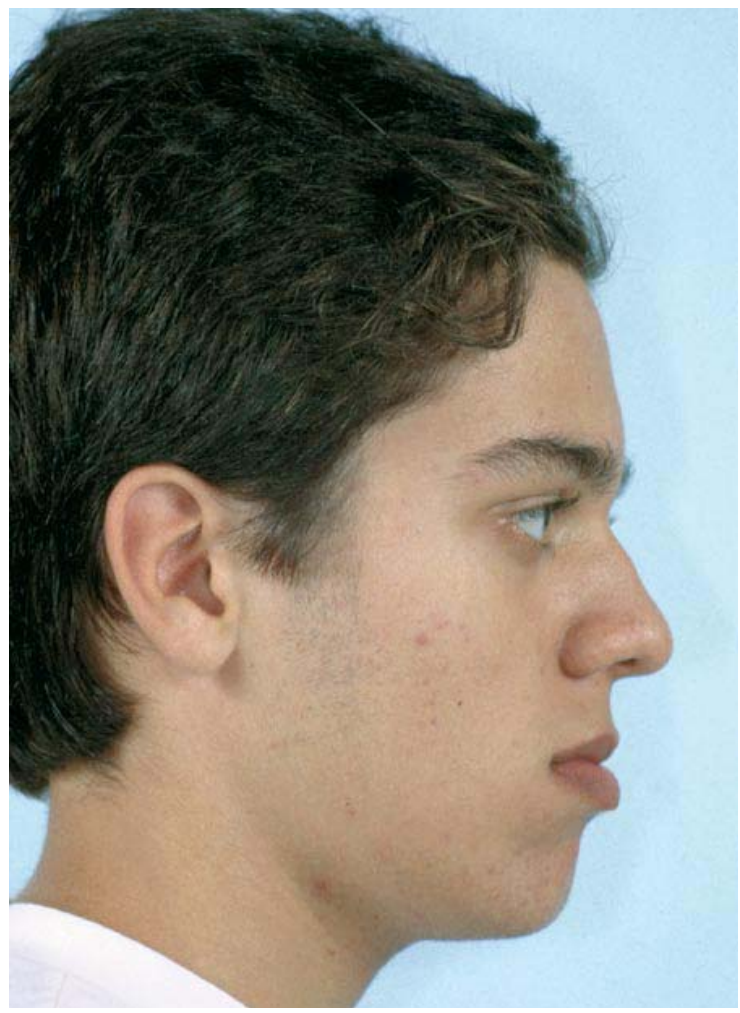

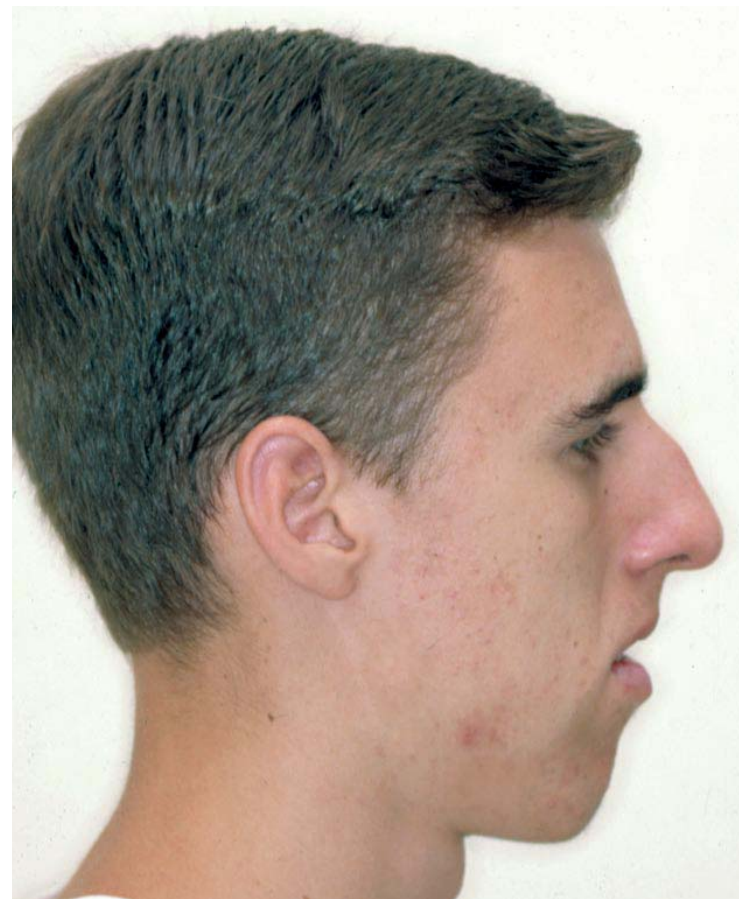




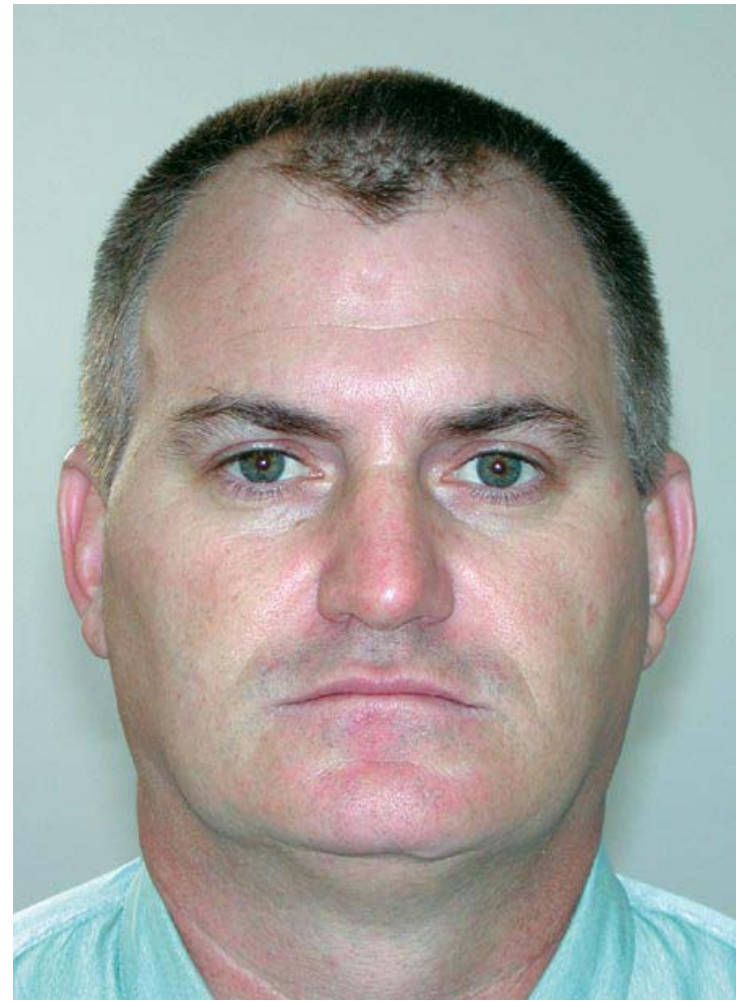

FIGURA 8 - Fotografias faciais frontal e lateral de paciente Padrão Face Curta.

pela deficiência nas dimensões verticais, lábios comprimidos, maxila com expressão adequada e excesso da linha queixo-pescoço, devido à rotação anti-horária da mandíbula (Fig. 8). A convexidade do perfil está, normalmente, reduzida e o paciente apresenta pouca exposição dos incisivos superiores no repouso e no sorriso.

A utilização dos conceitos já estabelecidos pela literatura ortodôntica, aplicados sob essa nova perspectiva, permite maior previsibilidade aos tratamentos ortodônticos e tranqüilidade ao profissional, que se torna apto a utilizá-los.

\section{CONSIDERAÇÕES CLÍNICAS E CONCLU- SÕES}

Esse trabalho teve por objetivo primário sugerir termos que favorecem a comunicação entre os diversos profissionais envolvidos na Odontologia estética, e dos mesmos com o paciente.

Observamos, entretanto, após incluir a Análise

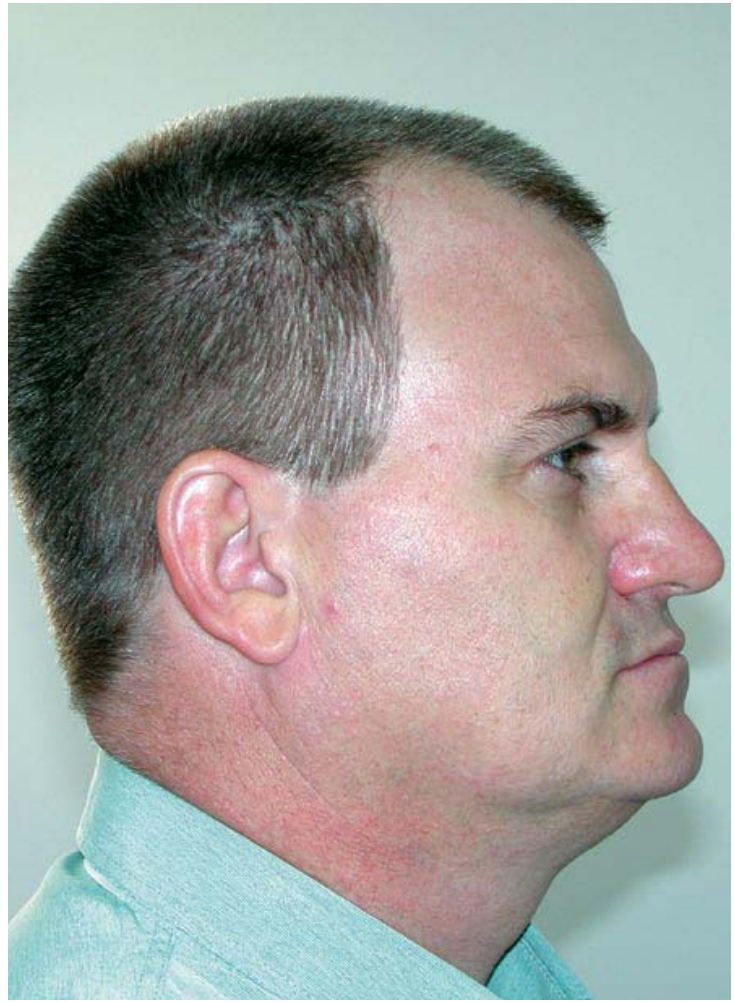

Facial Subjetiva como rotina na atividade clínica, que a classificação estética do paciente é mais um instrumento diagnóstico, que tem sua importância aumentada por ser o parâmetro pelo qual o paciente e as pessoas com as quais ele convive vão avaliar os resultados do tratamento.

Segundo Capelozza ${ }^{6}$, e baseados nesse estudo, concluímos que faces agradáveis são exceções e, geralmente, não dependem do dentista para atingirem ou permanecerem nesse estágio. Porém, uma vez exigindo intervenção odontológica, seja ela ortodôntica ou não, exigem do profissional um cuidado extremo para a preservação e acentuação das características de agradabilidade.

Os pacientes classificados como esteticamente desagradáveis e pertencentes aos Padrões II, III, Face Longa e Face Curta apresentam discrepâncias esqueléticas, as quais necessitam de tratamentos, que incluem muitas vezes cirurgias ortognáticas para corrigir o erro ósseo, normalmente grave. 
Essa classificação da estética pode, muitas vezes, definir a necessidade de cirurgias em casos limítrofes, nos quais um tratamento ortodôntico compensatório limitado ${ }^{6}$ pode ser realizado, obtendo uma melhora oclusal, sem, entretanto, promover um incremento estético do paciente na pirâmide de agradabilidade. Ou seja, o mesmo continuaria com a classificação de estética facial desagradável. A esses pacientes deve ser oferecida a oportunidade de mudança de nível, possível com a associação da Ortodontia com a Cirurgia e, muitas vezes, Implantodontia, Periodontia, Dentística e Prótese.

Os pacientes esteticamente aceitáveis são a maioria. O plano de tratamento dos mesmos, como dos anteriores, deve ser feito com a premissa da melhoria estética. Aqueles que não apresentam discrepâncias esqueléticas ou más oclusões com repercussão facial devem ser submetidos a tratamentos ortodônticos corretivos, associados a recursos de outras áreas envolvidas com a estética, que resultam em uma melhora da agradabilidade, pelo menos do sorriso, área de interesse futuro de nossas pesquisas. Aos portadores de discrepâncias esqueléticas que não maculam significativamente a estética facial, o tratamento ortodôntico compensatório primário é a melhor opção, pois permite uma melhora na estética do sorriso, função adequada e preservação das características de aceitabilidade.

Portanto, a classificação da estética facial torna próximos o ortodontista, profissionais de outras especialidades e a expectativa do paciente, além de oferecer parâmetros morfológicos importantes para decisões diagnósticas muitas vezes duvidosas.

Outros resultados deste estudo, como a comparação com o índice de agradabilidade na visão frontal, além da comparação entre os diferentes grupos de avaliadores, já foram parcialmente publicados $^{6}$, mas serão compreensivamente abordados em publicações posteriores.

Enviado em: janeiro de 2006 Revisado e aceito: abril de 2006

\title{
Subjective Facial Analysis
}

\begin{abstract}
Introduction: facial analysis has been an important diagnostic method since the beginning of Orthodontics. Many authors have tried to define references of beauty to be reached with orthodontic treatment. This preoccupation is in accordance with patient expectation with orthodontic treatment. The main motivation for them is esthetic improvement. To solve it successfully orthodontists must know witch parameters the population use for esthetic evaluation. With suggest, through this paper, the Subjective Facial Analysis, esthetic and morphologic. Aim: to evaluate the application of the analysis proposed. Methods: it was asked a heterogeneous group (14 orthodontists, 12 laymen, 7 artists) to classify 100 photographs of facial profile as esthetically pleasant (grades 7, 8 or 9), acceptable (grades 4,5 or 6 ) or unpleasant (grades 1, 2 or 3). Eigthy nine percent of the sample was esthetically acceptable, $8 \%$ esthetically unpleasant and $3 \%$ esthetically pleasant. The nose and the chin were the structures of the facial profile more frequently related by appraisers (38.35\% and $18.9 \%$ respectively) as responsible for the unpleasant esthetic appearance. Conclusion: subjective Facial Analysis is a diagnostic tool, important because is the parameter used by patients and relatives to evaluate the results of orthodontic treatment.
\end{abstract}

Key words: Facial analysis. Esthetic. Orthodontics.

\section{REFERÊNCIAS}

1. ALCALDE, R. E.; JINNO, T.; ORSINI, M. G.; SASAKI, A.; SUGIYAMA, R. M.; MATSUMURA, T. Soft tissue cephalometric norms in japanese adults. Am J Orthod Dentofacial Orthop, St. Louis, v. 118 , no. 1 , p. 84-89, July 2000

2. AUGER, T. A.; TURLEY, P. K. The female soft tissue profile as presented in fashion magazines during the 1900s: a photographic analysis. Int J Adult Orthodon Orthognath Surg, Chicago, v. 14, no. 1, p. 7-18, 1999.

3. BITTNER, C.; PANCHERZ, H. Facial morphology and malocclusions. Am J Orthod Dentofacial Orthop, St. Louis, v. 97, no. 4, p. 308-315, Apr. 1990.

4. BRONS, R. Facial harmony: standards for orthognathic surgery and orthodontics, 1998. London: Quintessence, 1998. p. 166.

5. BURSTONE, C. J. The integumental profile. Am J Orthod, St. Louis, v. 44, no. 1, p. 25, Jan. 1958.

6. CAPELOZZA FILHO, L. Diagnóstico em Ortodontia. Maringá: Dental Press Editora, 2004. 
7. CUNNINGHAM, M. R. Measuring the physical in physical at tractiveness: quasi-experiments on the sociobiology of female facial beauty. J Pers Soc Psychol, Washington, D. C., v. 50 no. 5, p. 925-935, May 1986

8. CZARNECKI, S. T.; NANDA, R. S.; CURRIER, G. F. Perceptions of a balanced facial profile. Am J Orthod Dentofacial Orthop, St. Louis, v. 104, no. 2, p.180-187, Aug. 1993.

9. COX, N. H.; VAN DER LINDEN, F. P. G. M. Facial harmony. Am J Orthod Dentofacial Orthop, St. Louis, v. 60, no. 2, p. 175-183, Aug. 1971.

10. EVANKO, A. M.; FREEMAN, K.; CISNEROS, G. J. Mesh diagram analysis: developing a norm for Puerto Rican Americans. Angle Orthod, Appleton, v. 67, no. 5, p. 381-388, 1997.

11. GIDDON, D. B. Aplicações ortodônticas de estudos psicológicos e perceptuais da estética facial. In: SADOWSKY, P. L.; PECK S.; KING, G. LASKIN, D. M. Atualidades em Ortodontia. São Paulo: Premier, 1997. p. 79-88.

12. HALL, D.; TAYLOR, R. W.; JACOBSON, A.; SADOWSKY, P. L.; BARTOLUCCI, A. The perception of optimal profile in african americans versus white americans as assessed by orthodontists and the lay public. Am J Orthod Dentofacial Orthop, St. Louis, v. 118, no. 5, p. 514-525, Nov. 2000.

13. HERZBERG, B. L. Facial esthetic in relation to orthodontic treatment. Angle Orthod, Appleton, v. 22, no. 1, p. 3-22, Jan. 1952.

14. HOWELLS, D. J.; SHAW, W. C. The validity and reliability of ratings of dental and facial attractiveness for epidemiologic use. Am J Orthod, St. Louis, v. 88, no. 5, p. 402-408, Nov. 1985

15. JEFFERSON, Y. Skeletal types: keys to unraveling mystery of facial beauty and its biologic significance. J Gen Orthod, MiIwaukee, v. 7, no. 2, p. 7-25, June 1996.

16. JOHNSTON, V. S.; FRANKLIN, M. Is beauty in the eye of the beholder? Ethol Sociobiol, [New York], v. 14, p.183-199, 1993.

17. JONES, D.; HILL, K. Criteria of facial attractiveness in five population. Hum Nature, Hawthorne, v. 4, no. 3, p. 271-296, 1993

18. KHAN, R. S.; HORROCKS, E. N. A study of adult Orthodontic patients and their treatment. Br J Orthod, London, v. 18, no. 3, p.183-194, Aug. 1991.

19. LANGLOIS, J. H.; ROGGMAN, L. A. Attractive faces are only average. Psychol Sci, Malden, v. 1, no. 2, p.115-121, Mar. 1990

20. LANGLOIS, J. H.; ROGGMAN, L. A.; MUSSELMAN, L. What is average and what is not average about attractive faces? Psychol Sci, Malden, v. 5, no. 4, p. 214-220, July 1994

21. LEW, K. K. K.; HO, K. K.; KENG, S. B.; HO, K. H. Soft-tissue cephalometric norms in chinese adults with esthetic facial profiles. J Oral Maxilofac Surg, Philadelphia, v. 50, no.11, p.1184-1189, Nov. 1992.

22. MAGANZINI, A. L.; TSENG, J. Y. K.; EPSTEIN, J. Z. Perception of facial esthetics by native chinese participants by using manipulated digital imagery techniques. Angle Orthod, Appleton, v. 70 no. 5 , p. 393-399, 2000

23. MANTZIKOS, T. Esthetic soft tissue profile preferences among the japanese population. Am J Orthod Dentofacial Orthop St. Louis, v.114, no.1, p.1-7, July 1998.

24. McKIERMAN, E. X. F.; McKIERMAN, F.; JONES, M. L. Psychological profiles and motives for adults seeking orthodontic treatment. Int J Adult Orthodon Orthognath Surg, Chicago, v. 7, no. 3, p.187-198, 1992.

25. MORRIS, W. An orthodontic view of dentofacial esthetics. Compendim Contin Educ Dent, Lawrenceville, v. 15, no. 3, p. 378-390, 1994

26. NANDA, R. S.; GHOSH, J. Harmonia entre os tecidos moles da face e o crescimento no tratamento ortodôntico. In: SADOWSKY, P. L. et al. Atualidades em Ortodontia. São Paulo: Premier, 1997. p. 65-78.

27. NEGER, M.; NEWARK, N. J. A quantitative method for the evaluation of the soft-tissue facial profile. Am J Orthod , St. Louis, v. 45 , no. 10, p. $738-751$, Oct. 1959.

28. NGUYEN, D. D.; TURLEY, P. K. Changes in the caucasian male facial profile as depicted in fashion magazines during the twentieth century. Am J Orthod Dentofacial Orthop, St. Louis, v. 114, no. 2, p. 208-217, Aug. 1998.
29. PECK, H.: PECK, S. A concept of facial esthetics. Angle Orthod, Appleton, v. 40, no. 4, p. 284-318, Oct. 1970.

30. PECK, S. Beauty is youth, youth is beauty? Sci News, Washington, D. C., v. 146, p.115, Aug. 1994

31. PECK, S.: PECK, L. Aspectos selecionados da arte e da ciência da estética facial. In: SADOWSKY, P. L.; PECK, S.; KING, G. LASKIN, D. M. Atualidades em Ortodontia. São Paulo: Premier, 1997. p. 99-116

32. PERRET, D. I.; MAY, K. A.; YOSHIKAWA, S. Facial shape and judgements of female attractiveness. Nature, Basingstoke, v. 368, no. 6468, p.1-4, Mar. 1994

33. PERRET, D. I.; LEE, K. J.; PENTON-VOAK, I.; ROWLAND, D. YOSHIKAWA, S: BURT, D. M. HENZL, S. P. CASTLES, D. L.; AKAMATSU, S. Effects of sexual dimorphism on facial attractiveness. Nature, Basingstoke, v. 394, no. 27, p. 884-887, Aug 1998.

34. PERRIN, F. A. C. physical attractiveness and repulsiveness. J Exp Psychol, Washington, D.C., v. 4, p. 203-217, 1921.

35. PHILLIPS, C.; TULLOCH, C.; DANN, C. Rating of facial attractiveness. Community Dent Oral Epidemiol, Copenhagen, v. 20 no. 4, p. 214-220, 1992.

36. RECHE, R. Análise do perfil facial feminino adulto jovem esteticamente agradável em fotografias padronizadas. 1999. Trabalho de Conclusão e Curso (Especialização)- Escola de Aperfeiçoamento Profissional da Associação Brasileira de Odontologia, Curitiba, 1999

37. REIS, S. A. B. Análise facial numérica e subjetiva do perfil e análise da relação oclusal sagital em brasileiros, adultos leucodermas, não tratados ortodonticamente. 2001. $271 \mathrm{f}$ Dissertação (Mestrado em Ortodontia)-Faculdade de Odontologia, Universidade Metodista de São Paulo, Piracicaba, 2001.

38. REIS, S. A. B. Estudo comparativo do perfil facial dos padrões I, II e III portadores de selamento labial passivo. R Dental Press Ortodon Ortop Facial, Maringá. No prelo.

39. RICKETTS, R. M. The biologic significance of the divine proportion and fibonacci series. Am J Orthod Dentofacial Orthop St. Louis, v. 81, no. 5, p. 351-370, May 1982.

40. TERRY, R. L.; DAVIS, J. S. Components of facial attractiveness. Percept Mot Skills, [S.L.], v. 42, p. 918, June 1976

41. TWEED, C. H. Evolutionary trends in Orthodontics, past, present, and future. Am J Orthod, St. Louis, v. 39, no. 2, p. 81-108, Feb. 1953.

42. VARELA M.; GARCIA-CAMBA, J. E. Impact of Orthodontics on the psychologic profile adult patients: a prospective study. Am J Orthod Dentofacial Orthop, St. Louis, v. 108, no. 2, p.142-148, Aug. 1995.

43. WUERPEL, E. H. Ideals and idealism. Angle Orthod, Appleton, v. 1, p. 14-31, 1931.
Endereço de correspondência

Silvia Augusta Braga Reis

Rua Timbiras 1560 sala 308 - Bairro lourdes

CEP: 30.140-061 - Belo Horizonte/MG

E-mail: silvia@ortoadultos.com.br 